\title{
BMJ Open Cross-sectional study on knowledge, attitude and prevalence of domestic violence among women in Kaduna, north-western Nigeria
}

\author{
Awawu Grace Nmadu (D) , ${ }^{1}$ Abubakar Jafaru, ${ }^{1}$ Tukur Dahiru, ${ }^{2}$ \\ Istifanus Anekoson Joshua, ${ }^{1}$ Bilkisu Nwankwo, ${ }^{1}$ Amina Mohammed-Durosinlorun ${ }^{3}$
}

To cite: Nmadu AG, Jafaru A, Dahiru T, et al. Crosssectional study on knowledge, attitude and prevalence of domestic violence among women in Kaduna, northwestern Nigeria. BMJ Open 2022;12:e051626. doi:10.1136/ bmjopen-2021-051626

- Prepublication history for this paper is available online. To view these files, please visit the journal online (http://dx.doi. org/10.1136/bmjopen-2021 051626).

Received 24 March 2021 Accepted 11 February 2022

Check for updates

(c) Author(s) (or their employer(s)) 2022. Re-use permitted under CC BY-NC. No commercial re-use. See rights and permissions. Published by BMJ.

${ }^{1}$ Department of Community Medicine, Faculty of Clinical Sciences, College of Medicine, Kaduna State University, Kaduna, Kaduna State, Nigeria ${ }^{2}$ Department of Community Medicine, College of Health Sciences, Ahmadu Bello University, Zaria, Nigeria ${ }^{3}$ Department of Obstetrics and Gynaecology, Faculty of Clinical Sciences, College of Medicine, Kaduna State University, Kaduna, Kaduna State, Nigeria

Correspondence to Dr Awawu Grace Nmadu; jumainmadu@gmail.com

\section{ABSTRACT}

Background Domestic violence is a global issue of public health concern with detrimental effects on women's physical, mental and social well-being. There is a paucity of community-based studies assessing the knowledge and attitude of women towards domestic violence in Nigeria.

Objective To assess knowledge, attitudes, prevalence and associated factors of domestic violence among women in a community in Kaduna, Nigeria.

Design A descriptive cross-sectional study.

Setting A selected community in Kaduna South Local Government Area in Kaduna State.

Participants In total, 170 women aged 15-49 years participated in the study.

Primary and secondary outcome measures The outcomes were knowledge, attitude and prevalence of domestic violence.

Results The mean age of the respondents was $28.7+7.9$ years. A total of $113(66.5 \%)$ respondents had high level of knowledge about domestic violence with 114 (67.1\%) having non-tolerant attitudes towards domestic violence. The lifetime prevalence and 12-month prevalence of domestic violence were $47.1 \%$ and $35.3 \%$, respectively. The results of logistic regression identified the educational status of women as a significant predictor of knowledge of domestic violence $($ adjusted OR $(\mathrm{aOR})=0.32 ; 95 \% \mathrm{Cl} 0.15$ to 0.68 ), while marital status ( $\mathrm{aOR}=0.21 ; 95 \% \mathrm{Cl} 0.05$ to 0.96$)$, occupation of women ( $\mathrm{aOR}=2.49 ; 95 \% \mathrm{Cl} 1.13$ to 5.49$)$, their tolerance of wife beating $(\mathrm{aOR}=0.33 ; 95 \%$ $\mathrm{Cl} 0.15$ to 0.72 ) and their partners' consumption habit of alcohol/substance use (aOR=7.91; 95\% Cl 3.09 to 20.27) were identified as significant predictors of the women's experience of domestic violence.

Conclusion Domestic violence was relatively high among women. Though a majority had high level of knowledge about domestic violence, a significant third had tolerant attitudes towards it. Appropriate health interventions need to be implemented by governmental and relevant stakeholders to target negative attitudes and address associated factors of domestic violence against women.

\section{INTRODUCTION}

Domestic violence (DV) against women is a hidden global epidemic that occurs in all countries with detrimental effects on the
Strengths and limitations of this study

- This study provides context to knowledge attitude and prevalence of domestic violence among women in Kaduna State, north-western Nigeria, using the Conflict Tactics Scale.

- The response rate was high (100\%) despite the sensitive nature of the issue.

- Only women were interviewed and the potential for biased responses on their husband's/partner's behavioural characteristics cannot be discounted.

- This study was cross-sectional, so a causal relationship could not be confirmed.

health and well-being of women. The physical, mental, sexual and reproductive health of millions of women and families is adversely affected by DV. It has dire social and economic consequences and costs for families, communities and societies. ${ }^{1}$ DV has been increasingly recognised as a serious public health problem and a violation of women's human rights. $^{2}$ The right to life and the right to bodily integrity are core fundamental rights that are protected under the international law. The WHO defines DV as the intentional use of physical force or power, threatened or actual, against oneself, another person, against a group or a community that results in or has a high likelihood of resulting in injury, death, psychological harm, maldevelopment or deprivation. ${ }^{2}$ Although both men and women can be victims, the prevalence and detrimental effects of DV, particularly of sexual and physical violence, are higher among women. ${ }^{3}$

DV occurs internationally in both developing and developed countries, irrespective of culture, religion or socioeconomic class, and differs in prevalence, types and extent from one country to another. ${ }^{4}$ According to the World's Women 2020: Trends and 
Statistics report, around one-third of women worldwide have experienced physical and/or sexual violence by an intimate partner. ${ }^{5}$ Some $18 \%$ of women have experienced such violence in the last 12 months. In extreme cases, violence against women is lethal. Globally, an estimated 137 women are killed by their intimate partner or a family member every day. The countries of sub-Saharan Africa (SSA) have very high levels of violence against women and mostly where socioeconomic status is low and education is limited. ${ }^{6}$ In Nigeria, one in four women have experienced a form of DV, common among young women and dwellers of rural areas. ${ }^{7}$ The National Demographic and Health Survey (NDHS) 2008 and 2013 data revealed that $18 \%$ and $16 \%$ of ever-married women were reported having experienced physical or sexual DV from their male spouse, respectively. ${ }^{89}$ The issue of DV is more relevant now during the COVID-19 pandemic as the lockdowns and the social and economic impacts have more likely increased the exposure of women to abusive partners and known risk factors while limiting their access to services.

Studies have revealed several factors that perpetuate DV. These include cultural factors like cultural beliefs about the superiority of men and inferiority of women, cultural acceptance of violence as a private affair and societal acceptability of violence as a means of resolving discords. ${ }^{10}$ Legislation and policies that discriminate against women also provide avenues for perpetuating act of violence against women. ${ }^{11}$ Sadly, legal provisions in about 155 countries have been shown to be discriminatory against women. ${ }^{11}$ Some of these include laws placing men as heads of households, legally requiring wives to obey their husbands, legal restrictions on types of jobs women can do and laws that deny women the same right to access land as men. ${ }^{12} 13$

Nigeria, despite being a signatory to many international laws protecting women from DV such as the Convention on the Elimination of All Forms of Discrimination Against Women, African Charter on Human and Peoples' Rights, among others, has failed to domesticate such legislation at the national level, with just a few states adopting the legislation with variable success in terms of implementation. ${ }^{7}$

Scholars have strongly argued that attitude changes towards DV is an essential component for sustaining DV interventions. ${ }^{14}$ Improved knowledge can increase the management of DV while improved attitudes can reduce the acceptance and justification of DV. ${ }^{15}$ Public awareness campaigns and other interventions delivered via television, radio, newspapers and other mass media can be effective for altering attitudes towards gender norms. ${ }^{16}$ The most successful have been those that sought to understand their target audience and engage with its members to develop content. There is a paucity of communitybased studies assessing the knowledge and attitude of women towards DV in Kaduna State. This study assessed the current levels of knowledge, attitude to and prevalence of DV and associated factors among women in a community in north-western Nigeria.

\section{MATERIALS AND METHODS}

This cross-sectional study was carried out in Kaduna South Local Government Area (LGA), Kaduna State, northwestern Nigeria, from June to July 2019. It has an area of $59 \mathrm{~km}^{2}$ and an estimatedpopulation of $402390 .{ }^{17}$ The settlement is typically urban and located within Kaduna metropolis-the capital of the fourth largest State in the most populous African country in the world. Women of reproductive age group between the ages of 15 and 49 years were included in the study. The minimum sample size was determined using a single population formula $(\mathrm{n}=\mathrm{z} 2 \mathrm{p}(1-\mathrm{p}) / \mathrm{d} 2)$, where $\mathrm{z}$ is the normal SD set at 1.96 , with a confidence level specified at $95 \%$ and a tolerable margin of error (d) at $5 \%$, considering $10 \%$ non-response rate and prevalence of violence $(\mathrm{p})$ at $11 \%{ }^{18}$ The calculated sample size for this was 165 which was approximated to 170 ; the women were selected through a multistage sampling technique.

\section{Data collection tool and procedures}

A pretested, structured, interviewer-administered questionnaire adapted from the Revised Conflict Tactics Scale (CTS-2) was used to assess DV among women in Kaduna South LGA. ${ }^{19}$ The instrument has previously been validated in Nigeria and $\mathrm{SSA}^{720}$ and was thus a good measure of DV for this cultural context and region. The attitude towards wife abuse was assessed using the Revised Attitudes toward Wife Abuse Scale. ${ }^{21}$ The questionnaire had four sections: the first dealt with sociodemographic characteristics of the study participants; the second had questions addressing knowledge on DV; the third had questions that assessed the participant's attitudes towards DV. The final part had questions to measure the participants' experience of DV. Data were collected by trained research assistants. The principal investigator supervised the data collection procedures. Data collectors were trained for 2 days on interviewing techniques, the purpose of the study, the importance of privacy, confidentiality of the respondents, the sensitivity of the topic and approach to the interviewees. Information about the study was provided to each participant and their anonymity and the confidentiality of their responses, voluntary participation and right to withdraw at any stage was emphasised, after which informed verbal consent was obtained. The collected data were cross-checked on each day of data collection for consistency and completeness.

\section{Data analysis}

Data were analysed using the Statistical Package for Social Sciences (SPSS V.25). Descriptive statistics were used to examine the sample characteristics and to estimate the prevalence of DV.

DV as the outcome of interest was measured as physical violence, sexual violence and emotional violence which included experiences of one or several of the following acts of abuse by a current or former partner in a woman's lifetime and the 1 year preceding the study ${ }^{7}$ : 
Physical violence: (1) pushing, shaking or throwing something at her; (2) slapping her; (3) twisting her arm or pulling her hair; (4) punching her with his fist or hitting her with something harmful; (5) kicking, dragging or beating her; (6) choking or burning her on purpose; and (7) threatening or attacking her with a weapon (eg, gun or knife).

Sexual violence: (1) forced sexual intercourse; (2) physically forcing her to perform any other sexual act when undesired; and (3) forcing her with threats to perform sexual acts when undesired.

Emotional violence: (1) humiliating her in public; (2) threatening to hurt or harm someone close to her; and (3) insulting or making her feel bad about herself.

The respondents' level of knowledge on DV was assessed using a set of five questions. A response of 'Yes' was graded 2, 'No' and 'Don't Know' were graded as 0 . Overall knowledge scores were calculated from the knowledge of DV and subquestions. Overall knowledge scores were further calculated by summing the responses. The maximum score was 20. Knowledge score was divided into two categories: high $(\geq$ median $)$ and low $(<$ median $)$.

Attitude was assessed as towards wife beating-categorical 'yes' or 'no' variables were created from responses to five scenarios ${ }^{7}$ : if she goes out without telling him; if she neglects the children; if she argues with him; if she refuses to have sex with him; and if she burns food. An answer of 'yes' to at least one scenario would mean that the respondent justified wife beating and was coded as 1 , while an answer of 'no' in all scenarios meant the respondent did not justify wife beating and was coded as 0 . A respondent was considered to have experienced DV if she answered 'yes' to at least one act of any of the forms of violence (physical, sexual or emotional).

Bivariate and multivariable logistic regression analyses were performed to explore the association between independent and dependent variables. Associated factors with $\mathrm{p}<0.05$ in the bivariate analysis were included in multivariate logistic regression analysis. ORs, $95 \%$ CIs and $p$ values were calculated for each independent variable. For bivariate and logistic analysis, 'don't know' responses from participants were reclassified as 'No'.

\section{Patient and public involvement}

Participants or the public were not involved in the design, or conduct, or reporting, or dissemination plans of our research.

\section{RESULTS}

The characteristics of the respondents are shown in table 1. A total of 170 women responded to the survey, giving a response rate of $100 \%$. The responders were mainly Hausa by ethnicity at $31.8 \%$ (54), married $64.1 \%$ (109), in monogamous relationships $81.1 \%$ (139), had tertiary education $50.6 \%$ (86), had between one and four children $57.1 \%(97)$ and of an average age of $28.7+7.9$ years, a majority of $41.2 \%$ (70) in the age group of 25-34
Table 1 Sociodemographic characteristics of the respondents $(n=170)$

\begin{tabular}{|c|c|c|}
\hline Variables & Frequency & Percentage \\
\hline \multicolumn{3}{|l|}{ Age group (years) } \\
\hline $15-24$ & 59 & 34.7 \\
\hline $25-34$ & 70 & 41.2 \\
\hline $35-44$ & 31 & 18.2 \\
\hline$\geq 45$ & 10 & 5.9 \\
\hline \multicolumn{3}{|l|}{ Tribe } \\
\hline Hausa & 54 & 31.8 \\
\hline Igbo & 23 & 13.5 \\
\hline Yoruba & 25 & 14.7 \\
\hline Others & 68 & 40.0 \\
\hline \multicolumn{3}{|l|}{ Religion } \\
\hline Islam & 59 & 34.7 \\
\hline Christianity & 111 & 65.3 \\
\hline \multicolumn{3}{|l|}{ Marital status } \\
\hline Single & 48 & 28.2 \\
\hline Married & 108 & 63.5 \\
\hline Divorced/widowed & 14 & 8.2 \\
\hline \multicolumn{3}{|l|}{ Educational level } \\
\hline None & 16 & 9.4 \\
\hline Primary & 13 & 7.6 \\
\hline Secondary & 56 & 32.9 \\
\hline Tertiary & 85 & 50.0 \\
\hline \multicolumn{3}{|l|}{ Family types } \\
\hline Monogamous & 139 & 81.8 \\
\hline Polygamous & 31 & 18.2 \\
\hline \multicolumn{3}{|l|}{ Parity } \\
\hline None & 47 & 27.6 \\
\hline $1-4$ & 97 & 57.1 \\
\hline 5 and above & 26 & 15.3 \\
\hline \multicolumn{3}{|l|}{ Occupation } \\
\hline Unemployed & 82 & 48.2 \\
\hline Employed & 88 & 51.8 \\
\hline \multicolumn{3}{|l|}{ Estimated income } \\
\hline Less than 100000 & 162 & 95.3 \\
\hline$\geq 100000$ & 8 & 4.7 \\
\hline \multicolumn{3}{|c|}{$\begin{array}{l}\text { Respondents' financial } \\
\text { dependence on a partner }\end{array}$} \\
\hline Yes & 64 & 37.6 \\
\hline No & 106 & 62.4 \\
\hline \multicolumn{3}{|l|}{$\begin{array}{l}\text { Partner consumes } \\
\text { alcohol/drugs }\end{array}$} \\
\hline Yes & 39 & 22.9 \\
\hline No & 131 & 77.1 \\
\hline
\end{tabular}

years. Fifty-two per cent of the women (88) were employed with $95.3 \%$ (162) of them earning less than 100000 naira per month. About 23\% (39) of the respondents' partners consumed alcohol or other substance drugs. 
Table 2 Descriptive statistics of knowledge on domestic violence $(n=170)$

\begin{tabular}{|c|c|c|}
\hline \multirow[b]{2}{*}{ Components of knowledge } & \multicolumn{2}{|l|}{ yes } \\
\hline & Frequency & Percentage \\
\hline Have you heard of domestic violence? & 150 & 88.2 \\
\hline An act of domestic violence occurs when a husband/partner slap/beats his wife/partner. & 152 & 89.4 \\
\hline An act of domestic violence occurs when a husband/partner humiliates/insults his wife/partner. & 139 & 81.8 \\
\hline
\end{tabular}

As shown in table 2, 88.2\% (150) of the respondents had heard about DV, $78.2 \%$ (133) identified DV by financial neglect, $89.4 \%$ (152) by slapping/beating, $81.8 \%$ (139) by insult/humiliation and $76.5 \%$ (130) by sex against her will.

The majority of the respondents at $66.5 \%$ (113) had high knowledge about DV while a significant $33.5 \%$ (57) had low knowledge about DV.

The overall lifetime prevalence of DV among women was found to be $47.1 \%$ while the overall prevalence of DV in the last 12 months among the women was $35.3 \%$. The lifetime prevalence of physical abuse, emotional abuse and sexual abuse was $28.8 \%, 44.1 \%$ and $22.9 \%$, respectively, while in the last 12 months the prevalence of physical abuse, psychological abuse and sexual abuse was $15.3 \%, 32.4 \%$ and $13.5 \%$, respectively (figure 1). About $16 \%(15.8 \%)$ of women had experienced all forms of violence concurrently and $26.5 \%$ of women experienced physical and emotional violence concurrently.

About two-thirds of the respondents $(67.1 \%, 114)$ felt there was no justified situation for a man to beat his partner. Twenty per cent (34) of the respondents justified a man beating his partner when a woman goes out without telling him, $22.9 \%$ (39) when she neglects her children, $14.7 \%$ (25) when she argues with her partner, $16.5 \%$ (28) when she refuses to have sex with her partner and $8.2 \%$ (14) when she burns food (table 3 ).

Bivariate analysis showed statistically significant associations between women's knowledge of DV and their level of education and occupation (table 4).

Significant associations were found between lifetime experience of DV and respondents' marital status $\left(\chi^{2}=6.46 ; p=0.04\right)$, educational level $\left(\chi^{2}=3.26 ; p=0.01\right)$, occupation $\left(\chi^{2}=5.20 ; \mathrm{p}=0.02\right)$ and respondent partners' consumption of alcohol/substance drugs $\left(\chi^{2}=21.36\right.$; $\mathrm{p}=0.001)$. Experience of DV in the past 12 months was only associated with respondents' partners consumption of alcohol/substance drugs $\left(\chi^{2}=29.55 ; p=0.001\right)$. A significant association was found between attitude towards wife beating and the level of education of respondents $\left(\chi^{2}=11.96 ; \mathrm{p}=0.008\right)$ (table 5).

The level of knowledge on DV was not associated with the attitude towards DV concerning wife beating $\left(\chi^{2}=3.26\right.$; $\mathrm{p}=0.07$ ). The odds of having high knowledge about DV was significantly lesser in those with lower levels of secondary education as compared with those with tertiary education (adjusted OR (aOR) $=0.32 ; 95 \%$ CI 0.15 to 0.68$)$ (table 6$)$.

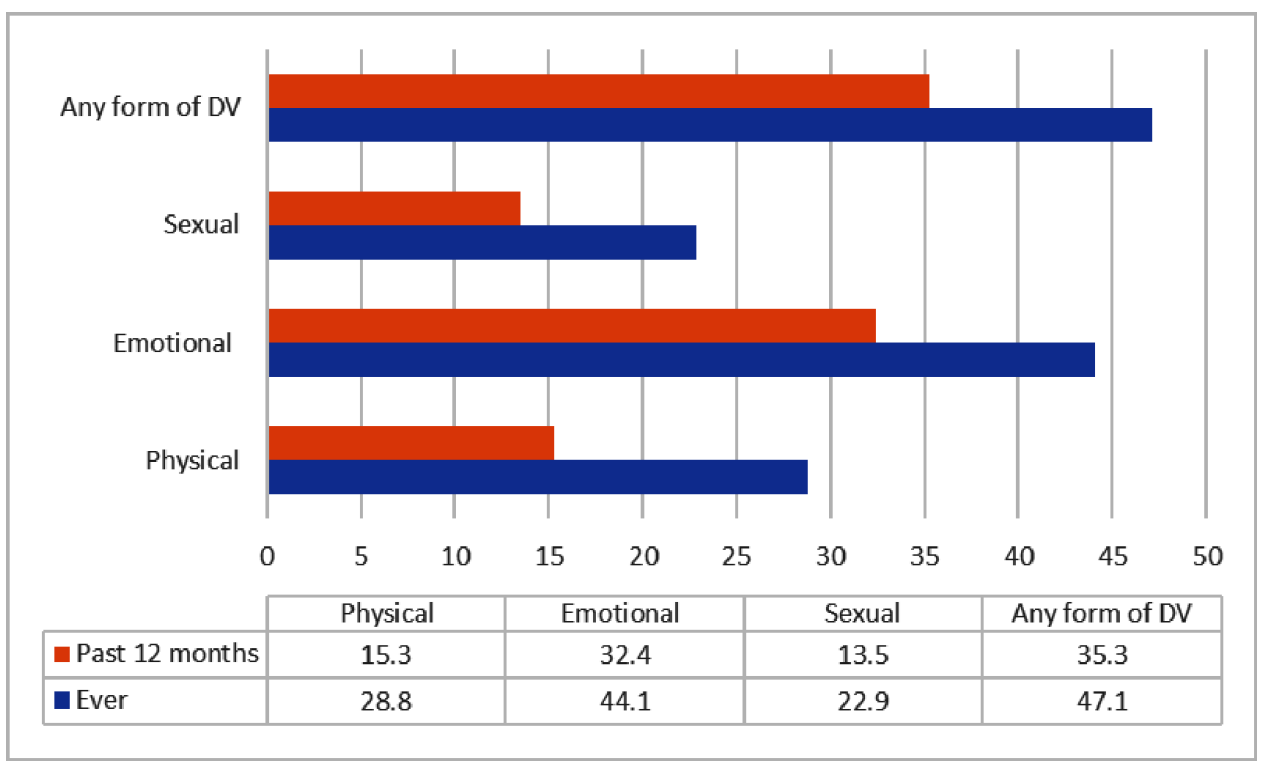

Figure 1 Proportion of respondents who reported experience of any form of domestic violence (DV) and the different forms of DV. 


Table 3 Respondents' attitudes towards domestic violence
$(n=170)$

\begin{tabular}{lll}
\hline Husband/partner is justified & & Yes \\
\cline { 2 - 3 } $\begin{array}{l}\text { in hitting or beating his wife/ } \\
\text { partner }\end{array}$ & Frequency & Percentage \\
\hline $\begin{array}{l}\text { If she goes out without telling } \\
\text { him. }\end{array}$ & 34 & 20.0 \\
If she neglects children. & 39 & 22.9 \\
If she argues with him. & 25 & 14.7 \\
$\begin{array}{l}\text { If she refuses to have sex with } \\
\text { him. }\end{array}$ & 28 & 16.5 \\
\hline If she burns food. & 14 & \\
\hline
\end{tabular}

Married women had lesser odds of experiencing DV as compared with women who were divorced/widowed $(\mathrm{aOR}=0.21 ; 95 \%$ CI 0.05 to 0.96$)$. Those with no formal education had greater odds of experiencing DV as compared with those with tertiary education $(\mathrm{aOR}=4.35$; $95 \%$ CI 0.93 to 20.33). Those whose partners consumed alcohol had greater odds of experiencing DV as compared with those whose partners did not $(\mathrm{aOR}=7.91 ; 95 \%$ CI 3.09 to 20.27 ) (table 7 ).

\section{DISCUSSION}

Women in this study generally had high knowledge about DV, but about a significant third had low knowledge. This was comparable to the findings of similar studies conducted in Sokoto, north-western Nigeria. ${ }^{22} 23$ Though the majority of the women had non-tolerant attitudes towards DV, about a significant third had tolerant attitudes. The level of knowledge on DV did not translate into the same level of attitude $\left(\chi^{2}=3.26 ; \mathrm{p}=0.071\right)$, contrary to previous findings of better knowledge and less tolerant attitudes towards DV. ${ }^{24}$ Furthermore, the prevalence of DV was high in our study population, close to $50 \%$ of women had experienced at least one type of DV in their lifetime and $35.5 \%$ of women had experienced DV within the past 12 months.

The knowledge and attitude to DV among women in this study were associated with their level of education. This is in agreement with similar studies in Africa which found that the higher the level of education, the more likely women had better knowledge and less tolerant attitudes to DV. ${ }^{2325}$ Educational empowerment interventions have been shown to be important strategies for changing attitude towards and prevention of $\mathrm{DV}^{26-28}$ In our study, the multivariable analysis showed the educational status of women as the final predictor of the level of knowledge of women about DV. This was similar to the findings from similar studies that showed higher levels of education associated with better knowledge and less accepting attitudes towards DV, ${ }^{24}{ }^{29}$ and in contrast, a study in Sri Lanka did not show an association between education and women's knowledge of DV. ${ }^{30}$
The lifetime prevalence of DV obtained in this study was much higher than the estimated findings of the NDHS 2013, which showed a lifetime prevalence of about $20 \%{ }^{31}$ The lifetime prevalence of DV in this study is also higher than the global and African regional estimates of violence against women at $30 \%$ and $37 \%$, respectively. ${ }^{32}$ This study reported higher lifetime prevalence than the findings of $42 \%$ in Kenya, $27 \%$ in Malawi, 32\% in Rwanda and $33 \%$ in Zimbabwe. ${ }^{33}$ Studies from the Democratic Republic of Congo and Zambia have, however, reported higher lifetime prevalence (52\% and $48 \%$, respectively) than were found in our study. The finding from our study was also higher than the findings from another study conducted in the northern part of Nigeria which reported a lifetime prevalence of $42 \% .^{34}$ This highlights the wide variability of the prevalence of DV against women across and within different countries. This variability could probably be in part due to differences in definition and measurement of DV. With regard to the measurement of DV, some studies had different outcome variables from spousal or partner exposure, such as exposure to interparental violence as the main explanatory variable, ${ }^{31}$ some studies explored DV using the three forms of DV (physical, sexual and emotional) as explored in this study, ${ }^{31}$ while in some studies emotional violence was not included in the analysis. ${ }^{32}$ Though a number of studies used the CTS, these were modified versions and not standardised across the studies as also in our study. ${ }^{31}{ }^{33}$ The Nigeria study cited above used a different scale (Composite Abuse Scale). ${ }^{34}$ Variability in prevalence of DV could also be related to differences in scope of studies, differences and peculiarities in culture and traditions across and within regions. This highlights the importance of conducting additional studies to provide more information relating to the contextual variability of DV.

Nigeria is a patriarchal society and the cultural norms that encourage DV may be one of the reasons for the high prevalence of DV in Nigeria and other countries with similar patriarchal cultural norms. The recent lockdowns as a result of the COVID-19 pandemic may also be a contributing factor to the relatively high prevalence of DV in the study population in the last 12 months prior to the study, considering that studies have documented an upsurge in DV around the world during the COVID-19 pandemic lockdown. 3536

Similar to the findings of a study conducted in Malaysia, our study found emotional violence to be the most common type of violence, followed by physical and sexual violence. ${ }^{37}$ The combination of physical and psychological abuse was depicted to be the most commonly occurring form of violence in this study, and a similar picture was seen in other studies as well. ${ }^{38} 39$

Similar to the findings from other studies, our study showed that violence was multiple in nature, and most of the women were subjected to more than one type of violence. ${ }^{40}{ }^{41}$ Our study showed that $15.8 \%$ of women had experienced all forms of violence concurrently which was higher than the findings from studies in rural 
Table 4 Associations between sociodemographic characteristics of respondents and knowledge of domestic violence $(n=170)$

\begin{tabular}{|c|c|c|c|c|}
\hline \multirow[b]{2}{*}{ Variable } & \multicolumn{2}{|c|}{ Level of knowledge } & \multirow[b]{2}{*}{ Test statistic } & \multirow[b]{2}{*}{$P$ value } \\
\hline & High & Low & & \\
\hline \multicolumn{5}{|l|}{ Age (years) } \\
\hline $15-24$ & $38(64.4)$ & $21(35.6)$ & $\chi^{2}=5.16$ & 0.16 \\
\hline $25-34$ & $52(74.3)$ & $18(25.7)$ & & \\
\hline $35-44$ & $16(51.6)$ & $15(48.4)$ & & \\
\hline$\geq 45$ & $7(70.0)$ & $3(30.0)$ & & \\
\hline \multicolumn{5}{|l|}{ Tribe } \\
\hline Hausa & $32(59.3)$ & $22(40.7)$ & $\chi^{2}=2.42$ & 0.49 \\
\hline Igbo & $16(69.6)$ & $7(30.4)$ & & \\
\hline Yoruba & $19(76.0)$ & $6(24.0)$ & & \\
\hline Others & $46(67.6)$ & $22(32.4)$ & & \\
\hline \multicolumn{5}{|l|}{ Religion } \\
\hline Islam & $34(57.6)$ & $25(42.4)$ & $\chi^{2}=3.17$ & 0.08 \\
\hline Christianity & 79 (71.2) & $32(28.8)$ & & \\
\hline \multicolumn{5}{|l|}{ Marital status } \\
\hline Single & $32(66.7)$ & $16(33.3)$ & $\chi^{2}=0.18$ & 0.91 \\
\hline Married & $71(65.7)$ & 37 (34.3) & & \\
\hline Divorced & $10(71.4)$ & $4(28.6)$ & & \\
\hline \multicolumn{5}{|l|}{ Educational level } \\
\hline None & $8(50.0)$ & $8(50.0)$ & $\chi^{2}=13.23$ & $0.004^{*}$ \\
\hline Primary & $9(62.2)$ & $4(30.8)$ & & \\
\hline Secondary & $29(51.8)$ & 27 (48.2) & & \\
\hline Tertiary & $67(78.8)$ & $18(21.2)$ & & \\
\hline \multicolumn{5}{|l|}{ Occupation } \\
\hline Unemployed & $48(58.5)$ & $34(41.5)$ & $\chi^{2}=4.47$ & $0.03^{*}$ \\
\hline Employed & 65 (73.9) & $23(26.1)$ & & \\
\hline \multicolumn{5}{|l|}{ Estimated income } \\
\hline Less than 100000 & $108(66.7)$ & $54(33.3)$ & $\chi^{2}=0.06$ & 0.81 \\
\hline$\geq 100000$ & $5(62.5)$ & $3(37.5)$ & & \\
\hline \multicolumn{5}{|l|}{ Parity } \\
\hline None & $37(78.7)$ & $10(21.3)$ & & \\
\hline $1-4$ & $61(62.9)$ & $36(37.1)$ & $\chi^{2}=4.62$ & 0.10 \\
\hline$>5$ and above & 15 (57.7) & $11(42.3)$ & & \\
\hline
\end{tabular}

*Statistically significant, $p<0.05$.

Nepal and Vietnam. ${ }^{39} 42$ The possible explanation for the higher occurrence observed in our study could be due to increasing awareness about the DV.

Studies have shown variability of factors such as age, educational level, socioeconomic status, employment and marital status that influence the risk of experiencing $\mathrm{DV},{ }^{43-45}$ and these associations have not been consistent. Mixed results have been shown with regard to the age of women and their experience of DV. Some studies have shown that the risk of DV declines with age ${ }^{46}$ while others have shown variation with age ${ }^{47}$; our study did not find an association between DV and age.

In agreement with the previous studies in Nigeria, our study has shown that the odds of DV has increased among women who justified wife beating. ${ }^{48} 49$ Though a woman's non-approval of DV might not necessarily reduce her risk of experiencing it, her status is an important factor and has a role to play. However, some studies have found that the protective effect of women's status against DV is not present in culturally conservative contexts. ${ }^{50}{ }^{51}$ Studies 
Table 5 Associations between sociodemographic characteristics of respondents and experience of domestic violence $(n=170)$

\begin{tabular}{|c|c|c|c|c|}
\hline \multirow[b]{2}{*}{ Variables } & \multicolumn{2}{|c|}{ Ever experienced DV } & \multirow[b]{2}{*}{ Test statistic } & \multirow[b]{2}{*}{$P$ value } \\
\hline & No & Yes & & \\
\hline \multicolumn{5}{|l|}{ Age (years) } \\
\hline $15-24$ & $26(44.1)$ & $33(55.9)$ & $\chi^{2}=3.26$ & 0.35 \\
\hline $25-34$ & 30 (42.9) & $40(57.1)$ & & \\
\hline $35-44$ & $19(61.3)$ & $12(38.7)$ & & \\
\hline$\geq 45$ & $5(50.0)$ & $5(50.0)$ & & \\
\hline \multicolumn{5}{|l|}{ Tribe } \\
\hline Hausa & $23(42.6)$ & $31(57.4)$ & $\chi^{2}=1.54$ & 0.67 \\
\hline Igbo & $12(52.2)$ & $11(47.8)$ & & \\
\hline Yoruba & $14(56.0)$ & $11(44.0)$ & & \\
\hline Others & $31(45.6)$ & $37(54.4)$ & & \\
\hline \multicolumn{5}{|l|}{ Religion } \\
\hline Islam & $26(44.1)$ & $33(55.9)$ & $\chi^{2}=0.32$ & 0.57 \\
\hline Christianity & $54(48.6)$ & $57(51.4)$ & & \\
\hline \multicolumn{5}{|l|}{ Marital status } \\
\hline Single & $23(47.9)$ & $25(52.1)$ & $\chi^{2}=6.46$ & $0.04^{*}$ \\
\hline Married & $46(42.6)$ & $62(57.4)$ & & \\
\hline Divorced /widowed & $11(78.6$ & $3(21.4)$ & & \\
\hline \multicolumn{5}{|l|}{ Educational level } \\
\hline None & $13(81.3)$ & $3(18.8)$ & $\chi^{2}=11.03$ & $0.01^{*}$ \\
\hline Primary & $6(46.2)$ & $7(53.8)$ & & \\
\hline Secondary & $29(51.8)$ & 27 (48.2) & & \\
\hline Tertiary & $32(37.6)$ & $53(62.4)$ & & \\
\hline \multicolumn{5}{|l|}{ Occupation } \\
\hline Unemployed & $46(56.1)$ & $36(43.9)$ & $\chi^{2}=5.20$ & $0.02^{*}$ \\
\hline Employed & 34 (38.6) & $54(61.4)$ & & \\
\hline \multicolumn{5}{|l|}{ Estimated income } \\
\hline Less than 100000 & $77(47.5)$ & 85 (52.5) & & 0.72 \\
\hline$\geq 100000$ & $3(37.5)$ & $5(62.5)$ & & \\
\hline \multicolumn{5}{|l|}{ Family type } \\
\hline Monogamous & $65(46.8)$ & 74 (53.2) & $\chi^{2}=0.03$ & 0.87 \\
\hline Polygamous & $15(48.4)$ & $16(51.6)$ & & \\
\hline \multicolumn{5}{|l|}{ Parity } \\
\hline None & $19(40.4)$ & $28(59.6)$ & & \\
\hline $1-4$ & $46(47.4)$ & $51(52.6)$ & $\chi^{2}=2.02$ & 0.37 \\
\hline 5 and above & $15(57.7)$ & $11(42.3)$ & & \\
\hline \multicolumn{5}{|c|}{ Financial dependence on a partner } \\
\hline Yes & $30(46.9)$ & $34(53.1)$ & $\chi^{2}=0.001$ & 0.97 \\
\hline No & $50(47.2)$ & $56(52.8)$ & & \\
\hline \multicolumn{5}{|c|}{ Partner consumes alcohol/drugs } \\
\hline Yes & $31(79.5)$ & $8(20.5)$ & $\chi^{2}=21.36$ & $0.001^{*}$ \\
\hline No & $49(37.4)$ & $82(62.6)$ & & \\
\hline
\end{tabular}

*Statistically significant, $p<0.05$.

DV, domestic violence. 
Table 6 Multivariate logistic regression of predictors of knowledge of domestic violence $(n=170)$

\begin{tabular}{|c|c|c|c|c|}
\hline Variables & Categories & $P$ value & aOR & $95 \% \mathrm{Cl}$ \\
\hline \multirow[t]{3}{*}{ Educational level } & None & 0.05 & 0.34 & 0.10 to 1.00 \\
\hline & Primary & 0.56 & 0.67 & 0.18 to 2.45 \\
\hline & Tertiary & & 1 & \\
\hline Occupation & Unemployed & 0.25 & 0.67 & 0.33 to 1.34 \\
\hline
\end{tabular}

${ }^{*}$ Statistically significant, $p<0.05$.

aOR, adjusted OR.

have shown that men's justification of wife beating increased a woman's probability of experiencing intimate partner violence (IPV) even more. It has been reported that men's views of DV are stronger predictors of DV than women's views, as women's perception may be more descriptive or injunctive rather than what they think. ${ }^{33}$ This is an area that requires further research in the African context as there are limited studies in this area.

However, while other studies from Nigeria and SSA 75253 have reported higher rates of DV among women with lower levels of education, our study, in comparison to a study in India, ${ }^{50}$ did not find any significant association between educational level and DV in the logistic regression, suggesting that other factors contributed to the higher rates of DV among the women in our study population. Four variables were identified by logistic regression with higher odds of experiencing DV in our study population-being unmarried (divorced/widowed), unemployed, justifying wife beating and having partners who consumed alcohol/had substance use habits. This finding is consistent with other studies. ${ }^{49} 54$
The finding from our study is consistent with prior research and suggests marital status might be a significant predictor of DV, and being married might be 'protective' against DV. ${ }^{34556}$ Considering the fact that this is cross-sectional data and causal relationships cannot be determined or totally excluded either, for this study we apply the term protective in a loose manner not to indicate causality, but the possible direction of association. The results of a study conducted in China indicated that marital status predicted all forms of IPV and divorced women experienced more violence compared with married women. ${ }^{56}$ Similarly, a study in the USA reported unmarried women at higher risks of DV and within the unmarried status categories, and separated women at highest risks of both DV and acquaintance victimisation experiences as compared with never-married or divorced women. ${ }^{57}$ It has been hypothesised that unmarried women are more likely to participate in daily routines unaccompanied by other household members and perceived by motivated offenders to be more suitable targets without adequate guardianship. ${ }^{57}$

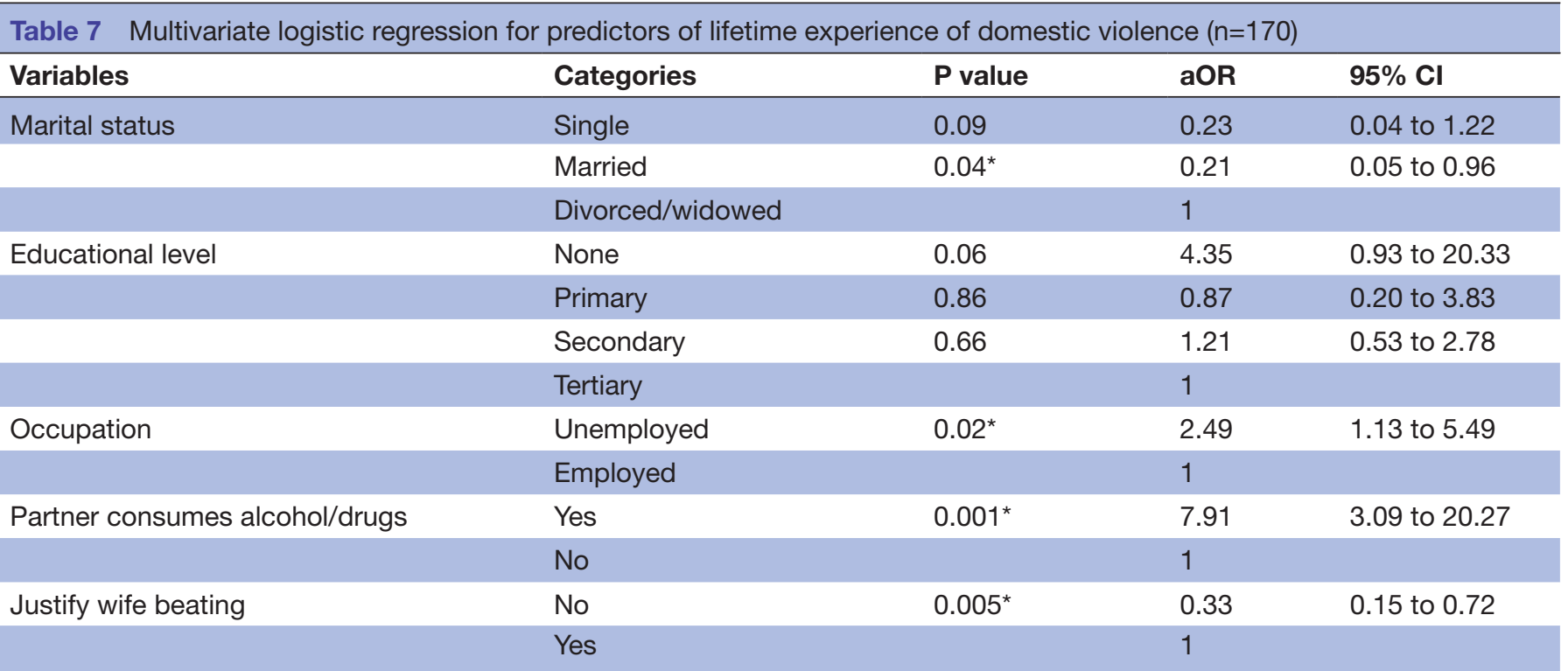

*Statistically significant, $p<0.05$.

aOR, adjusted OR. 
Similar to the findings in our study, women's employment appears to be associated with lower violence in some settings ${ }^{2540}$ but higher in others, ${ }^{44} 46$ with the suggestion that formal employment may be more protective than informal employment. ${ }^{53}$ Other studies reported no association between women's employment or income and DV. ${ }^{46}$ The links between a woman's employment status and risk of DV are complex and require further research to determine the contextual variations.

Alcohol and drug abuse has been widely documented in literature as playing facilitatory roles in either precipitating or exacerbating violence against women. ${ }^{589} \mathrm{Mech}-$ anisms have been thought to include and not limited to the disruption of the thinking process, manifestations of power, control and hostile personality. ${ }^{58}$ Our findings suggest that drugs and alcohol abuse should be taken into account when designing interventions for addressing IPV and family problems.

The findings of this study have potentially important implications for the development of effective strategies targeted at reducing the incidence of DV in the study population. Successfully addressing the complex issue of DV requires multipronged approaches that target factors that cut across individual, interpersonal, community and societal levels. Further studies are required to explore in depth the suggested factors that have been highlighted in this study as predictors of DV. There is a need to focus on empowering women and upgrading their socioeconomic status. Efforts should also be made to reach out to men to discourage excessive alcohol intake and associated substance abuse. Awareness-raising activities are still required to address the knowledge gaps and negative attitudes still prevalent among some women in the study population. Further studies are needed to explore how women cope with DV and whether their health needs are met; this was beyond the scope of this study. Additional studies are also required on global and regional scales to assess the impact of the COVID-19 pandemic on the landscape of DV among women.

\section{Strengths and limitations}

This is the first community-based study to collect information on the knowledge, attitude and prevalence of lifetime and past-year DV among women in Kaduna State as documented in the literature under the lens of the CTS. The response rate was high $(100 \%)$ despite the sensitive nature of the issue. The limitations of the study include a small sample size and exploration of a single LGA in the State which could limit the generalisation of results. However, the high prevalence elicited in this LGA, which is one of the largest in the State, contrasts with national values ${ }^{9}$ and underscores the importance of conducting further larger scale community-based studies. The fact that only women were interviewed and the potential for biased responses on their husband's/partner's behavioural characteristics cannot be discounted. Moreover, there is the possibility of under-reporting of the true extent of the problem due to the sensitivity of the violence issue. Also, not all possible confounders were fully explored from other studies such as partner's sociodemographic characteristics, history of DV in partners, among others. Finally, being a cross-sectional study, the analysis only provides evidence of the statistical associations between the variables, but the temporality of associations and causal directions cannot be established.

\section{CONCLUSION}

Our study found generally high level of knowledge about DV and a non-tolerant attitude towards it. There were high lifetime and past-year prevalence of DV among the women. The study provided information that DV could be related to marital status, respondent's employment status, partners' alcohol consumption/drug use habit and justification to wife beating. The study suggests the need for policies and programmes to empower women and improve employment opportunities. The inclusion of husbands/partners in DV prevention strategies is important to address issues related to alcohol and drug abuse that perpetuate violence against women. There is also a need to mount the interventions to cater for the high proportion of women who are exposed to DV in the community. Further longitudinal research is needed to better understand the complex range of factors related to DV among women.

Acknowledgements The authors thank the participants for participating in the study and the team who helped in data collection.

Contributors AGN conceived the study. AGN, AJ, TD, IAJ, BN and AM-D contributed to the survey design and data collection. AGN, AJ and TD contributed to data analysis. All authors contributed to the interpretation of data and intellectual revision of multiple drafts. AGN and AJ drafted the manuscript. All authors approved the final version of the manuscript. AGN is the designated guarantor for this document.

Funding The authors have not declared a specific grant for this research from any funding agency in the public, commercial or not-for-profit sectors.

Competing interests None declared.

Patient and public involvement Patients and/or the public were not involved in the design, or conduct, or reporting, or dissemination plans of this research.

Patient consent for publication Not required.

Ethics approval This study involves human participants and was approved by the Health Research and Ethics Committee (HREC) of the Barau Dikko Teaching Hospital-Kaduna State University (HREC reference number: 20-0052). Participants gave informed consent to participate in the study before taking part.

Provenance and peer review Not commissioned; externally peer reviewed.

Data availability statement Data are available upon reasonable request. Data are available upon reasonable request. All data relevant to the study are included in the article. Data are available on request by email to the corresponding author.

Open access This is an open access article distributed in accordance with the Creative Commons Attribution Non Commercial (CC BY-NC 4.0) license, which permits others to distribute, remix, adapt, build upon this work non-commercially, and license their derivative works on different terms, provided the original work is properly cited, appropriate credit is given, any changes made indicated, and the use is non-commercial. See: http://creativecommons.org/licenses/by-nc/4.0/.

ORCID iD

Awawu Grace Nmadu http://orcid.org/0000-0001-7813-6723

\section{REFERENCES}

1 World Health Organization. Respect women: preventing violence against women, 2019. Available: https://apps.who.int/iris/bitstream/ 
handle/10665/312261/WHO-RHR-18.19-eng.pdf?ua=1 [Accessed 16 Aug 2020].

2 World Health Organization. WHO Multi-country study on women's health and domestic violence against women, 2005. Available: https://apps.who.int/iris/bitstream/handle/10665/43310/ 9241593512_eng.pdf?sequence $=1$ [Accessed 16 Aug 2020].

3 Office for National Statistics (ONS). Domestic abuse in England and Wales: year ending, 2019. Available: https://www.ons.gov.uk/ peoplepopulationandcommunity/crimeandjustice/articles/domestic abuseprevalenceandtrendsenglandandwales/yearendingmarch2019 [Accessed 16 Aug 2020].

4 World Bank. Violence against women and girls. Available: https:// www.worldbank.org/en/topic/socialdevelopment/brief/violenceagainst-women-and-girls [Accessed 22 Aug 2020].

5 United Nations Statistics Division Demographic and Social Statistics. The World's Women 2020: Trends and Statistics, 2020. Available: https://worlds-women-2020-data-undesa.hub.arcgis.com/ [Accessed 20 Aug 2020].

6 Devries KM, Mak JY, Bacchus LJ, et al. Intimate partner violence and incident depressive symptoms and suicide attempts: a systematic review of longitudinal studies. PLoS Med 2013;10:e1001439.

7 Benebo FO, Schumann B, Vaezghasemi M. Intimate partner violence against women in Nigeria: a multilevel study investigating the effect of women's status and community norms. BMC Womens Health 2018:18:136.

8 Commission NP, Macro ICF. Nigeria demographic and health survey 2008: key findings. Calverton, MA: Author, 2009.

9 Commission NP, International ICF. Nigeria demographic and health survey 2013. Abuja, Nigeria: Author, 2014.

10 Aihie ON. Prevalence of domestic violence in Nigeria: implications for counselling. Ejoc 2010;2:1-8.

11 International Development Law Organization. Strengthening Women's Access to Justice, 2017. Available: https://www.idlo.int/ system/files/event-documents/IDLO\%20CN\%20-\%20Access\% 20to\%20Justice\%20for\%20Women\%20and\%20Girls\%20NO\% 20CONTACTS.PDF [Accessed 22 Aug 2020].

12 Hallward-Driemeier M, Hasan T. Empowering women: Legal rights and economic opportunities in Africa. World Bank Publications, 2012.

13 Slavchevska V, Doss CR, de la O Campos AP, et al. Beyond ownership: women's and men's land rights in Sub-Saharan Africa. Oxford Development Studies2021;49:2-22.

14 Whitaker DJ, Murphy CM, Eckhardt Cl, et al. Effectiveness of primary prevention efforts for intimate partner violence. Partner Abuse 2013:4:175-95.

15 Michau L, Horn J, Bank A, et al. Prevention of violence against women and girls: lessons from practice. Lancet 2015;385:1672-84.

16 World Health Organization. Promoting gender equality to prevent violence against women. (series of briefings on violence prevention: the evidence), 2009. Available: https://www.who.int/violence_injury prevention/violence/gender.pdf [Accessed 22 Aug 2020].

17 National Population Commission (NPC). Population census of the federal Republic of Nigeria 2006. Abuja, Nigeria: NPC, 2006.

18 Ajibola I, Aderonke O, Olatayo A. A, et al. Prevalence and correlates of intimate partner violence among men in a rural community of Oyo state, south-west Nigeria. Int J Community Med Public Health 2017:4:3991.

19 Straus MA, Hamby SL, Boney-McCoy S. The revised conflict tactics scales (CTS2) development and preliminary psychometric data. $J$ Fam Issues 1996:17:283-316.

20 Cools S, Kotsadam A. Resources and intimate partner violence in sub-Saharan Africa. World Dev 2017;95:211-30.

21 Yoshioka MR, DiNoia J, Ullah K. Attitudes toward marital violence: an examination of four Asian communities. Violence Against Women 2002;7:900-26.

22 Oche OM, Adamu H, Mallam SA, et al. Assessment of knowledge, attitude and experience of sexual violence among female employees in Sokoto Metropolis, northwest Nigeria. Afr J Reprod Health 2020;24:164-75.

23 Oche OM, Adamu H, Abubakar A, et al. Intimate partner violence in pregnancy: knowledge and experiences of pregnant women and controlling behavior of male partners in Sokoto, northwest Nigeria. Int J Reprod Med 2020;2020:1-10.

24 Abeid M, Muganyizi P, Massawe S, et al. Knowledge and attitude towards rape and child sexual abuse - a community-based crosssectional study in rural Tanzania. BMC Public Health 2015;15:1-2.

25 McCloskey LA, Boonzaier F, Steinbrenner SY, et al. Determinants of intimate partner violence in sub-Saharan Africa: a review of prevention and intervention programs. Partner Abuse 2016;7:277-315.

26 Anderson JN. Effects of education on victims of domestic violence. Family and Economic Issues 2015;32:140-51.
27 Taghdisi MH, Estebsari F, Dastoorpour M, et al. The impact of educational intervention based on empowerment model in preventing violence against women. Iran Red Crescent Med J 2014;16:e14432.

28 Niolon PH. Centers for disease control and prevention. preventing intimate partner violence across the lifespan: a technical package of programs, policies, and practices. Government Printing Office, 2017.

29 Onigbogi MO, Odeyemi KA, Onigbogi OO. Prevalence and factors associated with intimate partner violence among married women in an urban community in Lagos state, Nigeria. Afr J Reprod Health 2015:19:91-100.

30 Reyal HP, Perera KM, Guruge GN. Knowledge and attitude towards intimate partner violence among Ever-Married women: a crosssectional study from Sri Lanka. Advanced Journal of Social Science 2020;7:1-3.

31 Solanke BL. Does exposure to interparental violence increase women's risk of intimate partner violence? Evidence from Nigeria demographic and health survey. BMC Int Health Hum Rights 2018;18:1-3.

32 World Health Organization. Global and regional estimates of violence against women prevalence and health effects of intimate partner violence and non-partner sexual violence, 2013. Available: http://www. who.int/reproductivehealth/publications/violence/ 9789241564625/en/ [Accessed 18 Jul 2020].

33 Hindin MJ, Kishor S, Ansara DL. Intimate partner violence among couples in 10 DHS countries: Predictors and health outcomes. Macro International Incorporated, 2008.

34 Tanimu TS, Yohanna S, Omeiza SY. The pattern and correlates of intimate partner violence among women in Kano, Nigeria. Afr J Prim Health Care Fam Med 2016;8:e1-6.

35 Fraser E. Impact of COVID-19 Pandemic on Violence against Women and Girls, VAWG Helpdesk Research Report No 284. VAWG Helpdesk, 2020.

36 UN Women. COVID-19 and ending violence against women and girls, 2020. Available: https://www.unwomen.org/en/digital-library/ publications/2020/04/issue-brief-covid-19-and-ending-violenceagainst-women-and-girls

37 Shuib R, Endut N, Ali SH, et al. Domestic Violence and Women's Well-being in Malaysia: Issues and Challenges Conducting a National Study Using the WHO Multi-country Questionnaire on Women's Health and Domestic Violence Against Women. Procedia Soc Behav Sci 2013:91:475-88.

38 Abeya SG, Afework MF, Yalew AW. Intimate partner violence against women in Western Ethiopia: prevalence, patterns, and associated factors. BMC Public Health 2011:11:913.

39 Nguyen DV, Ostergren P-O, Krantz G. Intimate partner violence against women in rural Vietnam--different socio-demographic factors are associated with different forms of violence: need for new intervention guidelines? BMC Public Health 2008;8:55.

40 Deribe K, Beyene BK, Tolla A, et al. Magnitude and correlates of intimate partner violence against women and its outcome in Southwest Ethiopia. PLoS One 2012;7:e36189.

41 Ali TS, Asad N, Mogren I, et al. Intimate partner violence in urban Pakistan: prevalence, frequency, and risk factors. Int $J$ Womens Health 2011;3:105-15.

42 Sapkota D, Bhattarai S, Baral D, et al. Domestic violence and its associated factors among married women of a village development Committee of rural Nepal. BMC Res Notes 2016:9:1-9.

43 Chan YY, Rosman A, Ahmad NA, et al. Prevalence and factors associated with intimate partner violence among postpartum women attending government primary health care clinics in Malaysia. $J$ Fam Violence 2019;34:81-92.

44 Kapiga S, Harvey S, Muhammad AK, et al. Prevalence of intimate partner violence and abuse and associated factors among women enrolled into a cluster randomised trial in northwestern Tanzania. BMC Public Health 2017;17:190.

45 Lacey KK, West CM, Matusko N, et al. Prevalence and factors associated with severe physical intimate partner violence among U.S. black women: a comparison of African American and Caribbean blacks. Violence Against Women 2016;22:651-70.

46 Kishor S, Johnson K. Profiling domestic violence: a multi-country study. Studies in Family Planning 2005;36:259-61 https:// dhsprogram.com/pubs/pdf/od31/od31.pdf

47 García-Moreno C, Jansen HA, Ellsberg M. WHO multi-country study on women's health and domestic violence against women, 2005. Available: https://www.who.int/reproductivehealth/publications/ violence/24159358X/en/

48 Linos N, Slopen N, Subramanian SV, et al. Influence of community social norms on spousal violence: a population-based multilevel study of Nigerian women. Am J Public Health 2013;103:148-55

49 Uthman OA, Lawoko S, Moradi T. Factors associated with attitudes towards intimate partner violence against women: a comparative 
analysis of 17 sub-Saharan countries. BMC Int Health Hum Rights 2009:9:14.

50 Koenig MA, Ahmed S, Hossain MB, et al. Women's status and domestic violence in rural Bangladesh: individual- and communitylevel effects. Demography 2003;40:269-88.

51 Boyle MH, Georgiades K, Cullen J, et al. Community influences on intimate partner violence in India: women's education, attitudes towards mistreatment and standards of living. Soc Sci Med 2009;69:691-7.

52 Amegbor PM, Pascoe L. Variations in emotional, sexual, and physical intimate partner violence among women in Uganda: a multilevel analysis. J Interpers Violence 2021;36:NP7868-98.

53 Izugbara CO, Obiyan MO, Degfie TT, et al. Correlates of intimate partner violence among urban women in sub-Saharan Africa. PLOS One 2020;15:e0230508.

54 Oluwole EO, Onwumelu NC, Okafor IP. Prevalence and determinants of intimate partner violence among adult women in an urban community in Lagos, Southwest Nigeria. Pan Afr Med J 2020;36:345.
55 Yakubovich AR, Stöckl H, Murray J, et al. Risk and protective factors for intimate partner violence against women: systematic review and meta-analyses of Prospective-Longitudinal studies. Am J Public Health 2018;108:e1-11.

56 Lin K, Sun IY, Liu J, et al. Chinese women's experience of intimate partner violence: exploring factors affecting various types of IPV. Violence Against Women 2018;24:66-84.

57 Siddique JA, Age SJA. Age, marital status, and risk of sexual victimization: similarities and differences across Victim-Offender relationships. J Interpers Violence 2016;31:2556-75.

58 Bennett LW. Substance abuse by men in partner abuse intervention programs: current issues and promising trends. Violence Vict 2008;23:236-48.

59 Mair C, Cunradi CB, Gruenewald PJ, et al. Drinking context-specific associations between intimate partner violence and frequency and volume of alcohol consumption. Addiction 2013;108:2102-11. 